\title{
ARTICLES
}

\section{A DESCRIPTIVE STUDY TO ASSESS THE LEVEL OF STRESS AMONG FAMILY MEMBERS OF ORTHOPEDIC PATIENTS ADMITTED IN PARKASH HOSPITAL, AMRITSAR, PUNJAB}

\author{
Dr. Parkash Singh Dhillon* I Mr. Umar Aejaz Khan** I Mr. Firdous Shafiq Beigh** \\ Dr. Harjit Kaur*** I Ms. Jatinder Kaur*** \\ *Orthopedic Surgeon, Parkash Hospital, Amritsar, Punjab, India. \\ **B.Sc. Nursing $4^{\text {th }}$ year student, Parkash Hospital, Amritsar, Punjab, India. \\ ***Vice Principal, NRI College of Nursing, Amritsar, Punjab, India. \\ ****B.Sc. Nursing $4^{\text {th }}$ year student, NRI College of Nursing, Amritsar, Punjab, India.
}

DOI: http://doi.org/10.47211/idcij.2021.v08i03.016

ABSTRACT

Chronic stress causes biological disturbances. Admission in orthopaedic unit produces a crisis situation for both the patient and family members. If the event is not handled properly, the result may be prolonged physical and psychological instability of family member, a situation that may adversely affect patient outcome. The present researchstatement isto assess the level ofstressamong familymemberpatient admitted in orthopedic ward Amritsar.

Approach to research involves the description of plan to investigate phenomenon under study. In non - experimental approach, the research describes the phenomenon. A descriptive research approach will be used for present study. Non experimental research design is used assess the level of stress among family member patient admitted in orthopedic ward of Parkash hospital. In this study the sample size is 60 family member of patient admitted in orthopedic ward. It was concluded that almost any form of exercise or movement can increase your fitness level while decreasing your stress.

Key Words: Depression, Anxiety, stress.

\section{ABOUT AUTHORS:}

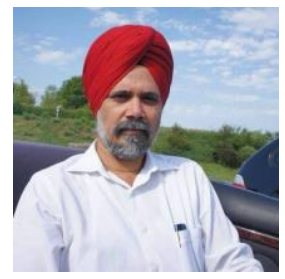

Author Dr. Parkash Singh Dhillon is Orthopedic Surgeon at Parkash Hospital, Amritsar, Punjab, India.

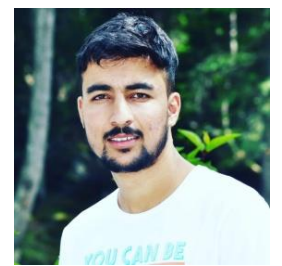

Author Mr. Umar Aejaz Khan is B.Sc. Nursing $4^{\text {th }}$ year student, Parkash Hospital, Amritsar, Punjab, India.

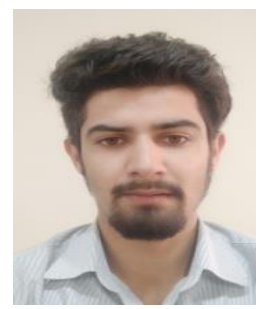

Author Mr. Firdous Shafiq Beigh is B.Sc. Nursing $4^{\text {th }}$ year student, Parkash Hospital, Amritsar, Punjab, India. 


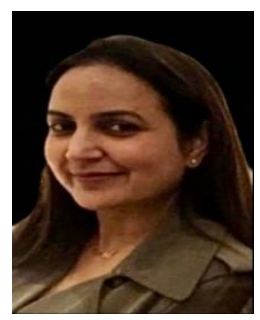

Author Dr. Harjit Kaur is working as Vice Principal, NRI College of Nursing, Amritsar, Punjab, India. She has Presented Papers at Various Seminars and Conferences.

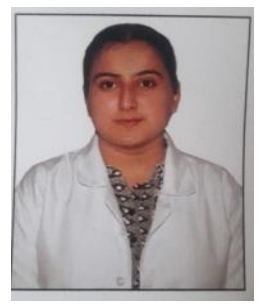

Author Ms. Jatinder Kaur is B.Sc. Nursing $4^{\text {th }}$ year student of Nursing, Amritsar, Punjab, India.

\section{INTRODUCTION}

Stress is derived from the Latin word 'string' which means 'to be drawn tightly'. Stress in human life is seen with tension, anxiety, worry, and pressure. It is accepted that a stress is an inevitable part of human life and it can cause either beneficial or detrimental effect on emotional intellectual, spiritual and social wellbeing. Chronic stress causes biological disturbances.

Admission in orthopaedic unit produces a crisis situation for both the patient and family members. During this period families deal with many stress including role changes financial concerns, uncertain patient prognosis. If the event is not handled properly, the result may be prolonged physical and psychological instability of family member, a situation that may adversely affect patient outcome.

\section{RESEARCH OBJECTIVES}

1. To assess the level of stress among family member of patient admitted in orthopedic ward.

2. To determine the relationship of level of stress among family member of patient with selected demographical variables such as age, gender, education, family income, hospital duration, marital status.

3. To provide guidelines regarding stress management to family of patient.

\section{AIM OF THE STUDY}

The aim of the study to assess the level of stress among family member of patient admitted in orthopedic ward.

\section{OPERATIONAL DEFINITION}

- STRESS: In this study, stress refers to an emotionally disruptive or unsettling condition of mind that occurs as a result of adverse external or internal influences during hospitalization of their patient which may in turn develop unfavourable response in their physical, psychological and social behaviour as measured by stress scale.

- ORTHOPEDIC PATIENT: It refers to fracture patients (male and female). It, on traction, plaster cast or bandage application and who are unable to move about freely.

- FAMILY MEMBER: Family member refers to mother, father or grandparents who are present with the patient in the hospital.

\section{DELIMITATIONS}

Studies were delimited to:

1. Family member of patient admitted in orthopaedic wards only

2. Family member those were willing to participate in the study

\section{REVIEW OF LITERATURE}

Review of literature plays an important role in the development of research project. An extensive review of literature provides the investigator a deeper insight into the problem. It is the key step in research process. 
S.k. Sharma (2005) ${ }^{7}$ review of literature is a broad, comprehensive, in depth, systematic and critical review of scholarly publication, unpublished printed or audiovisual material and personal communication.

Lynda L.(2009) $)^{12}$ A cross sectional study was conducted at India among 213 spouse of patient undergoing road accident to identify the psychological distress in spouse. $66 \%$ of the spouse met the criteria of distress, more in younger spouse. Distressed spouse used engagement coping strategies significantly more than non distressed and focused that stress were about worries about treatment recovery patient returning to work and about money.

\section{METHODOLOGY}

The present research statement is to assess the level of stress among family member patient admitted in orthopedic ward Amritsar.

\section{REARCH APPROACH:}

Approach to research involves the description of plan to investigate phenomenon under study. In non -experimental approach, the research describes the phenomenon. A descriptive research approach will be used for present study.

\section{RESEARCH DESIGN:}

Non experimental research design is used assess the level of stress among family member patient admitted in orthopedic ward of Parkash hospital.

RESEARCH SETTING:

The present study is conducted in the orthopedic hospital namely Parkash hospital situated at GT road putlighar Amritsar. SAMPLE SIZE:

In this study the sample size is 60 family member of patient admitted in orthopedic ward.

\section{DEVELOPMENT AND DESCRIPTION OF RESEARCH TOOL}

The research tool was selected and development by keeping in mind the objective of study, by reviewing theoretical sources, previous studies, internet and through discussion with field experts. The research tool divided into two parts.

\section{PART 1: Demographic Profile}

Demographic data (1-6 items) include age, gender, Education, family income, hospital duration, or marital status.

PART 2: Care giver stress assessment questionnaire

A standardized research tool CSAQ i.e. care giver stress assessment questionnaire is a very reliable tool to assess the stress level. It consists of tool 15 questions.

\section{PILOT STUDY}

Pilot study was conducted on 10 study subject within two days in orthopedic ward in parkash hospital. It was conducted to ensure the feasibility of the study.

\section{PROCEDURE OF DATA COLLECTION}

The data collection for the study was conducted in family member of patient admitted in orthopedic ward. A formal permission was obtained from HOD of the hospital. Study procedure explains the study subjects. Researcher first introducesherselftotherespondentandexplainedthepurposeof study.

\section{MAIN ANALYSIS}

OBJECTIVE 1: To assess the level of stress among family member of patient.

Table 2: Percentage of level of stress among family member of patients. $\mathrm{N}=60$

\begin{tabular}{|l|l|l|l|l|}
\hline Level of stress & $\mathbf{n}$ & Percentage & Mean & SD \\
\hline Mild stress (0-5) & 07 & $11.66 \%$ & 4.28 & 0.23 \\
\hline Moderate stress(6-10) & 31 & $51.66 \%$ & 12.83 & 0.94 \\
\hline
\end{tabular}

\section{MAJOR FINDINGS}

\section{Sample characteristics}

$>$ Distribution of study subject according to age of the family members of patients revealed that majority of family members of patients i.e. (16\%) were from $21-31$ years old followed by family members of patients aged $31-40$ years (12\%), $41-50$ years $(17 \%)$, above 60 years (5\%) and least number i.e. (10\%) 51 60 years was found.

$>$ Distribution of study subjects according to gender of family members of patients depicted that (37\%) female and (23\%) male are found.

$>$ Distribution of study subjects according to educational status of the family members of patients depicted that illiterate $(21 \%)$ and up to $5^{\text {th }}(16 \%)$. the few family members are graduations $(2 \%)$ and $10+2(8 \%)$ and least i.e. (13\%) from metric was found.

$>$ Distributions of study subject according to monthly family income of family members of patients the 


\section{ARTICLES}

majority of the monthly family income (38\%) were from $<5,000$ and family members earned the 5,000 10,000 were from (15\%) and 10,000-15,000 family earned were from (5\%)

$>$ Distribution of study subject according to duration of hospitals of family members of patients. The majority of the hospital duration the (41\%) were from 1-2 month and $(10 \%)$ duration of hospital in 3 month, (5\%) in 4 month and (3\%) duration of hospital in 6 month.

$>$ Distribution of study subject according to marital status of family members of patients. The majority of family members of patients i.e. (45\%) were married and (8\%) were unmarried and least i.e. widow/widower (5\%) and divorce $(2 \%)$.

\section{STRESS MANAGEMENT GUIDELINES:}

\section{EXERCISE:}

Almost any form of exercise or movement can increase your fitness level while decreasing your stress.

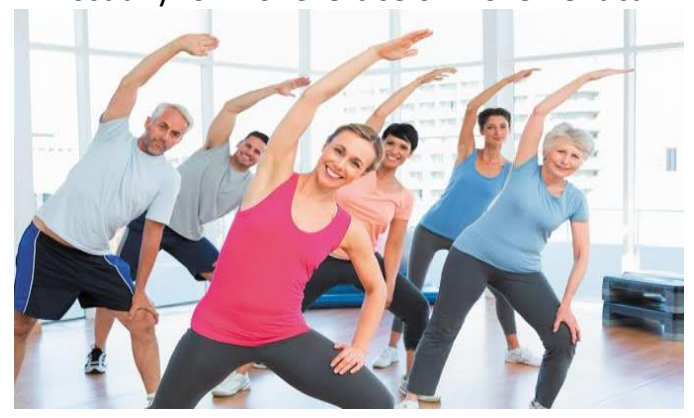

\section{YOGA:}

Stress and anxiety are everywhere. If they are getting the best of you, you might want to hit the mat and give YOGA a try.

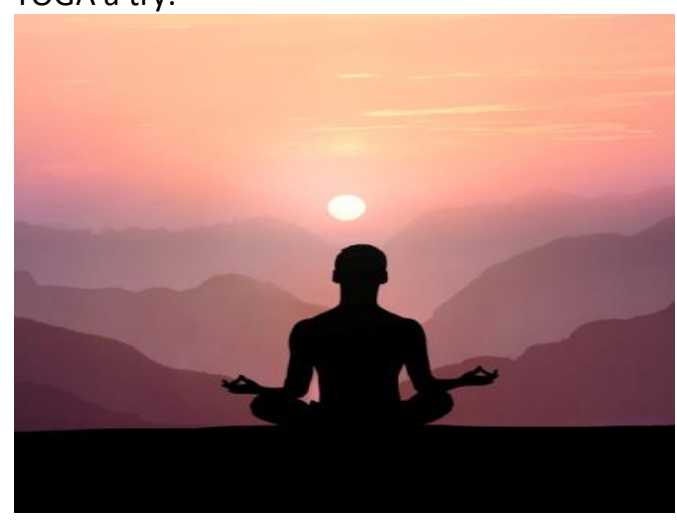

\section{QUIT SMOKING:}

Finding time to relax is also an important part of stress management when quitting smoking.

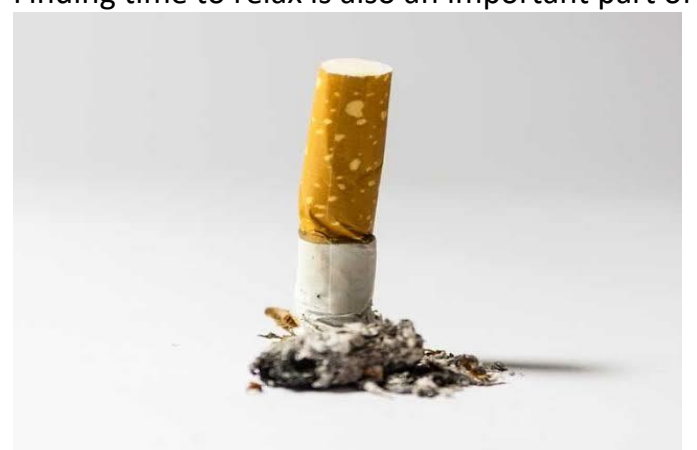

Similar study can be undertaken for an extended period of time.

The similar study can be conducted by selecting other variables. 


\section{ARTICLES}

\section{REFERENCES:}

1. Hans Selye, Stress and Coping of wives of patients with myocardial infraction. BMJ 1973 Apr, 14;2;101-03.

2. Lagarns \& Folkmor, Families in ICU, their needs and anxiety level. Intensive Care Nurse 2005;5(1):10-8.

3. The World Health Organization Descriptive study to assess the anxiety level of relatives of the patients admitted in ICU. Nightingale Nursing Times 2008 Sep;4(6-9):21-8.

4. Rodrigue RJ, MacNaughton K, Hoffman RG ,Grahampole J, Andres JM, Novak AD, Fenell RS. Stress and coping among mothers of children undergoing bone marrow, liver, kidney transplant. Psychosomatics 1997 Sep;38(5):478-86.

5. National Center for Health, Family care giving for parents with stroke, prevalence of caregiver depression. Stroke 1999;30:1478-85.

6. Buske M, Barclay L. Relatives of ICU patients may experience enduring stress, grief. J Gen Intern Med 2008 Sep.

7. Steven H, Schulz R. Prevalence and outcomes of caregivers after prolonged mechanicalventilationICUC1hest 2011 Dec; 140(6).

8. Salisbury MH Lamontage Coping strategies of relatives. Intensive and Critical Care Nursing 2004; 24:281-91.

9. Lariara S. Lyndaz, Principles and practice of psychiatric nursing. $8^{\text {th }}$ ed. New Delhi: Elsevier; 2005.

10. Morgan and King, Coping patterns and affective reaction under community crisis. Anxiety, stress and Coping 1995;8(3):185-201.

11. Dongre AR Mallampalli A, Parker SR, Kainad DR, Guntapalli K. Psychological impact of an ICU admission on relatives of patients in American and Indian hospital. Indian Journal of Critical Care Medicine 2011; 15(3):14756.

12. Idan S, Ebstein R, Kaitz M. Annual report 2010-2011 - division for development and public health. [Online]. Available from: URL:http://www.support.huji.ac.i/uploads/Publications/publications_annualreport2011.pdf

13. Thesimilarstudy can be replicated on alargesampletovalidateand generalizeits findings. 